\title{
International Conference for the Exploration of the Sea, Stockholm, 1899.
}

ON the invitation of the Swedish Government an International Conference met at Stockholm, in June, 1899, for the purpose of formulating a scheme for a combined investigation of the Northern Atlantic, the North Sea, and the Baltic in the interests of the sea-fisheries.

The delegates appointed to represent the different countries who took part in the Conference were as follows:-

Germany.-Prof. F. Heincke, Prof. V. Hensen, Dr. H. Herwig, Prof. O. Krümmel.

Denmark.-Captain C. F. Drechsel, Dr. M. Knudsen, Prof. C. G. J. Petersen.

Great Britain and Ireland.-Mr. W. Archer, Prof. D'Arcy W. Thompson, Sir John Murray.

Norway.-Dr. J. Hjort, M. K. Lehmkuhl, Prof. F. Nausen.

Holland.-Prof. P. P. C. Hoek.

Russia.-Prof. O. von Grimm.

Sweden.-Prof. P. T. Cleve, M. G. Ekman, Dr. N. R. Lundberg, Prof. O. Pettersson, Dr. F. Trybom, Prof. A. R. Åkerman.

The scheme recommended by the Conference was embodied in a series of formal resolutions, which were passed unanimously by all the delegates.

The following are these resolutions:-

Considering that a rational exploitation of the sea should rest as far as possible on scientific inquiry, and considering that international co-operation is the best way of arriving at satisfactory results in this direction, especially if in the execution of the investigations it be kept constantly in view that their primary object is to promote and improve the fisheries through international agreements, this International Conference resolves to recommend to the states concerned the following scheme of investigations which should be carried out for a period of at least five years. 
Programme for the Hydrographical and Biological work in the Northern parts of the Atlantic Ocean, the North Sea, the Baltic and adjoining Seas.

A.

THE HYDROGRAPHICAL WORK.

I.

The hydrographical researches shall have for their object: the distinction of the different water-strata, according to their geographical distribution, their depths, their temperature, salinity, gas-contents, plankton, and currents, in order to find the fundamental principles not only for the determination of the external conditions of the useful marine animals, but also for weather-forecasts for extended periods in the interests of agriculture.

II.

As the hydrographical conditions are subject to seasonal changes, and as these strongly influence the distribution and life-conditions of useful marine animals and the state of the weather and other general meteorological conditions, it is desirable that the observations should be made so far as possible simultaneously in the four typical months, February, May, August, and November, at definite points along the same determined lines.

III.

The observations referred to in II. would consist of :-

(a) Observations of temperature, humidity and pressure of the air every two hours; self-registering instruments for interpolation, and Assmann's aspirator should be used.

Opportunities should be afforded to the meteorological offices to make on board the ships physical observations on the higher levels of the atmosphere by means of kites.

The other meteorological observations are to be carried out according to the methods adopted by the meteorological offices of the nations represented.

The observations, meteorological as well as hydrographical, made on board the special steamers at the time of the survey in the typical months, are to be immediately worked out under the supervision of the central bureau (see C) for publication in a bulletin, wherein the conditions of the sea and the atmosphere are to be represented by tables and synoptical charts in co-operation with the meteorological institutes of the nations represented. 
(b) The temperature of the surface water shall be taken every two hours, or, when necessary, more frequently. It is desirable that selfregistering apparatus should be used for interpolation.

Observations on the vertical distribution of the temperature are to be taken at the points mentioned in II., and should be taken regularly at intervals of $0,5,10,15,20,30,40,50,75,100,150,200,250,300,400$ metres and so on; but all critical parts of the curve must be determined by extra-readings.

The bottom-temperature is to be investigated with all possible care.

(c) At every point and from every depth where the temperature is observed, a sample of water shall be collected for the determination of its salinity and density.

By salinity is to be understood the total weight in grammes of the solid matter dissolved in 1,000 grammes of water.

By density is to be understood the weight in grammes* of one cubic centimetre of water of the temperature in situ $t^{\circ}$, i.e. the specific gravity in situ referred to pure water of $+4^{\circ} \mathrm{C}\left(=S{\frac{t}{4^{\circ}}}^{\circ}\right)$.

For orientation, preliminary determination of the salinity should be made on board ship with expedient instruments, but the exact determination of the salinity and density of all samples shall take place in a laboratory for scientific work.

(d) At certain depths of the points mentioned in II., and elsewhere on the surface, water samples should be collected for analysis of the gasconstituents (oxygen, nitrogen, and carbonic acid).

IV.

For measurement of depth the unit to be adopted is the metre, together with which the depth may be also recorded in English fathoms.

Geographical points are to be referred to the longitude of Greenwich, and horizontal distances are to be expressed in sea-miles $(=1,852$ metres).

Thermometers to be used for the determination of the surface-temperature may be either centigrade or Fahrenheit, but for publication all numbers are to be reduced to centigrade.

In the centigrade thermometers the distance between two degreemarks should be at least $5 \mathrm{~mm}$. and the degree divided at least in two parts, the Fahrenheit thermometer to be divided in a corresponding manner.

The use of Pettersson's insulated water-bottle is recommended for moderate depths, and the thermometers used for this apparatus should

* Units of weight are here used instead of mass-units. 
have a space at least $10 \mathrm{~mm}$. between the marks of one degree, and the degree should be divided in ten parts.

For greater depths of the ocean Negretti-Zambra's or other thermometers of a similar type should be used.

The glass to be used for the thermometers as well as the thermometers should be tested and approved by the central bureau (see C, a).

For the determination of salinity and density, either chemical or physical methods may be adopted, provided that the salinity can be determined with an accuracy of 0,05 in a thousand parts (and the density up to 0,00004 ).

The determination of these constants can be founded either upon chemical analysis of the halogen by weighing or titration, or upon physical determination of the specific gravity by means of hydrostatical balance pycnometers and hydrometers, provided that measures be taken to exclude disturbances arising from thermal effects, capillarity, viscosity, etc.

The chemical analysis shall be controlled by physical methods, and the physical determinations by chemical analysis in the following manner:-

From every collection of samples examined at least three shall be selected and sent to the central bureau. Standard samples shall be sent in return.*

The specific gravity is to be represented in the tables by the formula $S\left(\frac{0^{\circ}}{4^{\circ}}\right)$.

v.

Samples for gas analysis are to be collected each time in a pair of sterilised vacuum tubes.

It is desirable that the existing tables of absorption of nitrogen and oxygen should be revised.

VI.

Qualitative plankton-observations should be made every six hours by pumping through a silk net (Nr. 18) for the space of fifteen minutes, and at the same time a sample of water (III. $c$ ) should be taken.

At the points mentioned in II. samples for quantitative analysis are to be collected according to the method of Prof. Hensen at different depths depending on the hydrographical circumstances.

Petersen's modification of Hensen's net is recommended.

* By standard water shall be understood samples of filtered sea-water, the physical and chemical properties of which are known with all possible accuracy by analysis, and statements of which are sent to the different laboratories, together with samples.

In respect to halogen the ordinary water-samples have to be compared with the standard water by analytical methods. 
Observations on transparency and colour of the water should be made at the points mentioned in II.

Opportunities should be afforded to bacteriological institutions to carry out investigations in the ocean.

VII.

Observations on currents and tides should be carried out as frequently as the circumstances allow.

The currents should be examined, when possible, by direct currentmeters and by surface and intermediate floats and by bottom-rollers.

The ship should be anchored occasionally in order to make frequent observations during a complete period of tide.

VIII.

It is desirable that a chart should be prepared of the bottom of the seas examined, showing the nature of the sea-bottom.

The description of the deposits is to be carried out on a definite plan, to be afterwards settled. (See Appendix III.)

IX.

The normal observations are to be carried out along the lines provisionally drawn on the annexed chart, where $R$ denotes the Russian, $F$ the Finnish, $S$ the Swedish, $G$ the German, $D a$ the Danish, $D u$ the Dutch, $N$ the Norwegian, and $B$ the British lines.

The special points are to be decided by the respective nations, and when once chosen the subsequent observations are to be repeated at the same points.

The particular instructions for the stations will be given by the respective nations, and the communications as to the extent and the nature of the observations shall take place through the central bureau. (See C, $a$ and $e$.)

$\mathrm{x}$.

It is desirable, in carrying out these investigations, to make use of regular liners, light-ships, etc., and coast stations for the purpose of taking temperature-observations and collecting samples of sea-water and plankton.

These observations are to be taken not only in the typical months but also during the intervening periods. 


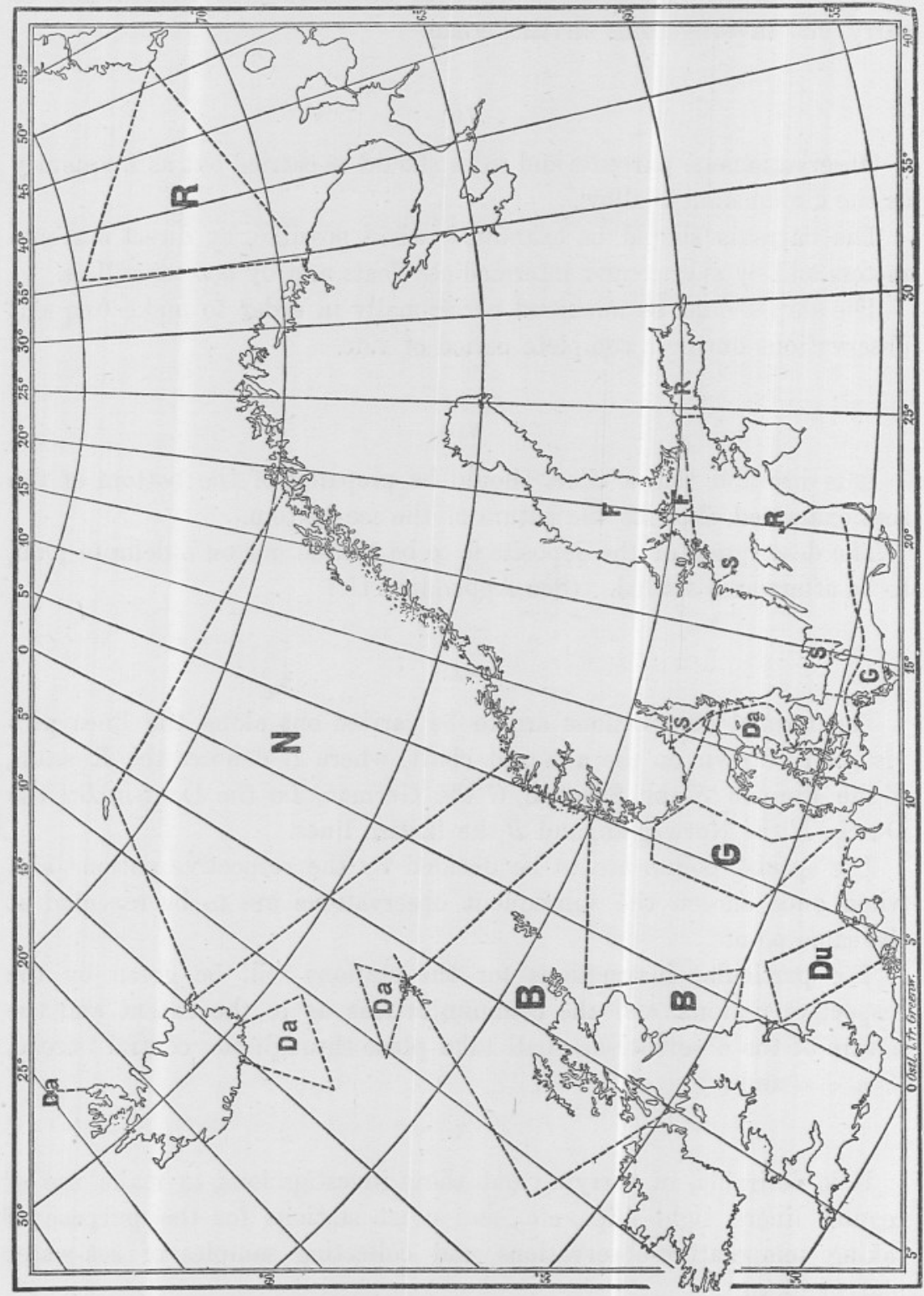

CHÅRT SHOWING THE LINES OF OBSERVATION RECOMMENDED BY THE STOCKHOLM FISHERIES CONFERENCE. 
B.

THE BIOLOGICAL WORK.

I.

(a) Determination of the topographical and bathymetrical distribution of eggs and larvæ of marine economic fishes; for example, by quantitative methods, such as those of Hensen, and with special reference to the most important species, such as plaice, cod and haddock, herring, etc. (See Appendix I.)

(b) Continued investigation of the life-history and conditions of life of young fishes of economic species in their post-larval stages and till they reach maturity, with special reference to their local distribution.

(c) Systematic observation of mature marketable fishes with reference to their local varieties and migrations, their conditions of life, nourishment (as, for instance, by investigation of the contents of the stomach), and natural enemies: also observations on the occurrence and nature of fish food at the bottom, the surface and intermediate waters down to depths of at least 600 metres. (See Appendix I.)

(d) Determination of periodic variations in the occurrence, abundance, and average size of economic fishes, and the causes of the same.

II.

(a) Experimental fishings on the known fishing grounds during the time of the fishery, as well as outside these areas and seasons.

(b) Preparation of uniform statistics of the experimental catches, with particulars of the number, species, size, weight, and condition of the fish; for example, as done on board the Garland by the Scottish Fishery Board.

(c) The uniform use of appropriate apparatus for the experimental capture of the different species and sizes of fish.

(d) The experimental marking and liberation of fish, for instance of plaice, on as large a scale as possible and over extensive areas; for example, as carried out by Dr. C. G. Joh. Petersen and Dr. T. W. Fulton (Reports of the Danish Biological Station and the Fishery Board for Scotland), and others. (See Appendix IV.)

III.

(a) It is desirable to collect uniform statistics of the number, weight, and value of the fish landed, of the means of capture, and of the persons engaged in the industry; for example, as in the General Reports of the Scottish Fishery Board. 
(b) It is desirable to collect material for the preparation of maps, showing the fishing grounds and the kinds of fishing there practised. (Cf. A. vIII.)

C.

ORGANISATION OF A CENTRAL BUREAU.

I.

The Conference recommends that there should be for the international hydrographical and biological researches of the seas an international council with a central bureau, furnished with a laboratory. (See Appendix II.) The central bureau will be:-

(a) To give uniform directions for the hydrographical and biological researches in accordance with the resolutions drawn up in the programme of the present Conference, or in accordance with such modifications as may be introduced later with the consent of the States represented.

(b) To control the apparatus and to ensure uniformity of methods.

(c) To undertake such particular work as may be entrusted to it by the participating Governments.

(d) To publish periodical reports and papers which may prove useful in carrying out the co-operative work.

(e) To decide the graphic representations, scales, signs, and colours to be used in the charts for the purpose of obtaining uniformity in the publications.

(f) To make, in connection with the investigations, application to the telegraph administrations for the purpose of obtaining determinations from time to time of the changes in the resistance of the cables which cross the areas in any direction.

II.

(a) The permanent International Council should consist of commissioners elected by the Governments interested. Each Government may appoint two commissioners, who may be represented at meetings by substitutes.

(b) The Council elects its president and vice-president, and appoints all officials connected with the central bureau. Should the general secretary represent hydrographical sciences, his principal assistant should represent the biological sciences, or vice versa.

(c) The Council shall draw up its own order of proceedings. 
(b) It is desirable to collect material for the preparation of maps, showing the fishing grounds and the kinds of fishing there practised. (Cf. A. vIII.)

C.

ORGANISATION OF A CENTRAL BUREAU.

I.

The Conference recommends that there should be for the international hydrographical and biological researches of the seas an international council with a central bureau, furnished with a laboratory. (See Appendix II.) The central bureau will be:-

(a) To give uniform directions for the hydrographical and biological researches in accordance with the resolutions drawn up in the programme of the present Conference, or in accordance with such modifications as may be introduced later with the consent of the States represented.

(b) To control the apparatus and to ensure uniformity of methods.

(c) To undertake such particular work as may be entrusted to it by the participating Governments.

(d) To publish periodical reports and papers which may prove useful in carrying out the co-operative work.

(e) To decide the graphic representations, scales, signs, and colours to be used in the charts for the purpose of obtaining uniformity in the publications.

(f) To make, in connection with the investigations, application to the telegraph administrations for the purpose of obtaining determinations from time to time of the changes in the resistance of the cables which cross the areas in any direction.

II.

(a) The permanent International Council should consist of commissioners elected by the Governments interested. Each Government may appoint two commissioners, who may be represented at meetings by substitutes.

(b) The Council elects its president and vice-president, and appoints all officials connected with the central bureau. Should the general secretary represent hydrographical sciences, his principal assistant should represent the biological sciences, or vice versa.

(c) The Council shall draw up its own order of proceedings. 
(d) The expenses of the central office are approximately estimated $£ 4,800$ ( 96,000 marks) yearly.

(e) The place of the central bureau, to be decided by the Governments concerned, shall at the same time be the residence of the general secretary, and should be conveniently situated for hydrographical and biological researches.

(f) It will be for the Governments concerned to decide among themselves the share to be borne by each.

Scheme for the expenditure of the Central Bureau.

1. General Secretary

500

3. President, for incidental expenses other than travel-

$$
\text { ling expenses . . . . . . } 200
$$

4. Vice-President, for incidental expenses other than travelling expenses . . . . 100

5. Office, laboratory, scientific and technical assistants, draughtsmen, clerks, servants, postage, telegrams, and similar expenses . . . . . . 2,250

6. Travelling expenses . . . . . . 300

Note: Travelling expenses of commissioners attending meetings of the Council shall be borne by their respective Governments.

7. Printing

$$
\begin{aligned}
& \text {. . . } 500 \\
& \text { 8. Incidental expenses . . . . . } 200 \\
& £ 4,800
\end{aligned}
$$

D.

It is desirable that these investigations should begin May 1st, 1901.

E.

The Conference declares that it is of the greatest importance, both for high-sea fisheries and for the weather forecasts for long periods, that the Faröe Islands and Iceland should be included in the European telegraph system as soon as possible.

$$
\text { F. }
$$

The relation between the quantity of halogen contained in the water and the density of the water shall be carefully investigated by an experimental revision of the tables compiled by Knudsen (Ingolf Exp. II. 37). The tables compiled by Makaroff, Krümmel, and others for the relation of specific gravity to density and salinity are likewise in urgent need of experimental revision. 
It is proposed to undertake these investigations in the technical institute at Copenhagen under the direction of a committee, consisting of Messrs. Sir John Murray, Knudsen, Pettersson, Nansen, Krümmel, H. N. Dickson, and Makaroff. The means for carrying out these works are to be requested from such learned societies as have funds for such purposes.

G.

The Conference recommends that these resolutions be brought by the nations concerned to the knowledge of the Governments of France and Belgium.

H.

In case the resolutions of the Conference should be accepted by the States, it is anticipated that some length of time will elapse before the organisation of the central bureau is completed. In the meantime the Governments may wish to possess an organisation in connection with this Conference which may be useful in constituting the Council and the central bureau.

The members of the third Committee, Akerman, Drechsel, Von Grimm, Herwig, Hoek, J. Murray, Nansen, Pettersson, hereby offer their services for this purpose.

STockноцм, June 23rd, 1899.

\section{APPENDIX I.}

In the quantitative estimation of pelagic fish eggs, and of the freeswimming larval stages that proceed from eggs, whether pelagic or demersal, the following considerations have to be kept in view :-

1. According to our present knowledge these floating objects are distributed over somewhat extensive areas, by the agency of winds, waves, and currents, in such a manner that a reasonable approximation of the total number of eggs present within the whole area may be arrived at by means of samples taken at certain points.

2 . Since the stages of development are not confined to the surfacewater, but partly, in the case of the riper eggs and larvæ, float deeper down, the net must be drawn, for purpose of quantitative estimation, in a vertical direction.

3 . The several series of observations must be carried out in a uniform manner in order that the results may be comparable. An example of the method of procedure lies to hand in the "Bericht der Kommission zur Untersuchung der deutschen Meere" on the experimental cruises 
undertaken by the German Seefischereiverein in the North Sea in the beginning of 1895, and minutely described by Hensen and Apstein.

The method employed is as follows: A funnel-shaped net with a ring $1 \frac{1}{2}$ metre in diameter, and capable of folding or closing up, and with a bag, to the end of which a beaker is attached, is let down perpendicularly to the bottom and then drawn up, until it hangs at the side of the ship. The net is then rinsed with a jet of water, so that its entire contents are washed down into the beaker at its extremity; the beaker is then detached and its contents removed.

It is usually impossible to examine this material at once, and it must consequently be suitably preserved for study ashore. The method of preservation should likewise be identical throughout the whole series of researches, as also should be the size and mesh of the net. The net is constructed of miller's gauze (or "bolting-cloth"), No. 3, as already used in the German deep-sea expeditions.

4. The ship has to be laid on a determined course, and an observation taken at least every twenty knots. If at the first glance eggs are present in considerable numbers in the catch (in which case over 200 eggs will be present), it will be necessary to take samples at shorter intervals, according to the judgment of the person in charge.

5. The eggs so obtained must be examined on shore for the purpose of estimating their number, and, so far as possible, of determining their species.

Specific determination of the larvæ, and even of the embryos in the eggs, is admittedly possible, and for such determination the works of M'Intosh, of Apstein, and the forthcoming publications of the Heligoland station, will afford material. The young eggs of the plaice, sole, etc., can be identified and therefore enumerated, while the eggs of the cod and haddock in the early stages of their development cannot, with our present knowledge, be distinguished from each other.

6. It is to be supposed that the hydrographic cruises in February, May, August, and November will also furnish material for determining the occurrence of eggs and larvæ, and will indicate when the time is come, or is approaching, for the commencement of systematic observation of the eggs. Since the spawning period differs somewhat in different years and in different parts of the sea, an agreement as to new courses of investigation in special areas of the various seas must be arranged through the central bureau or otherwise, on the basis of the results obtained during the hydrographic and other cruises.

7. Other methods for the numerical estimation of eggs and larvæ are by no means to be excluded, but should not interfere with or supplant the methods of research determined by international agreement.

Hensen. 


\section{APPENDIX II.}

In connection with the central bureau there should be a central laboratory, where, amongst other things, the following work might be carried out :-

1. The various methods for determining salinity, temperature, gases, plankton, etc., of the sea should be carefully tested, in order that standard methods may be fixed.

2. The various apparatus and instruments now used for hydrographical and biological research should be examined in order to settle which are the most trustworthy. Experiments may also be made to improve the apparatus and instruments, or to construct new and better ones.

3. Instruments and apparatus used in the investigations should be approved and tested at certain intervals at the central laboratory.

4. The water-samples sent by the workers of the participating states should be analysed and examined at the central laboratory, from which also samples of standard water should be provided. (See A. IV.).

5. If desired the water-, plankton-, or bottom-samples collected by the expeditions of the participating states could be examined at the laboratory on payment of a sum to be fixed by the international council.

6. In the central laboratory various important investigations of general interest for the hydrographical and biological researches may be carried out; e.g. analyses of the relation between the various saline constituents of the sea-water in the different parts of the ocean, analyses of the nature and quantity of plankton, as proposed by Prof. Cleve.

7. Facilities should be afforded to the participating states for sending students to the central laboratory to be trained for hydrographical and biological work.

8. The investigators of the participating states, or special expeditions, might, if desired, be supplied from the central laboratory with instruments, apparatus, and typical specimens of organisms and deposits for hydrographical and biological research at cost price.

Fridtuof Nansen. 


\section{APPENDIX III.}

\section{About Plankton Investigations.}

I. For estimating the amount of plankton I propose that a method be adopted founded on the following principles :-

1. Separation of the organic matter in a certain quantity of water, by means of centrifuge or by filtration.

2. Determination of the amount of carbon and nitrogen by combustion of the residuum in a vacuum tube by means of cupric oxide, and determination of the nitrogen and the dioxide of carbon.

\section{P. T. Cleve.}

II. As it is desirable to know the amount of fat in the plankton, we propose that a sample from each station be dried and extracted with ether. A small quantity of the non-extracted material may be tested on carbon or nitrogen, so that the total amount of fat in a certain quantity of water can be calculated, the amount of organic carbon or nitrogen (proposal I.) being known.

O. Pettersson.

P. T. Cleve.

III. It seems desirable that a systematic examination of the plankton close above the bottom be carried out, especially on the fishing-banks.

P. T. Cleve.

IV. It seems desirable to examine the bottom-fauna (benthos) of the fishing-banks of the North Sea at different seasons; for instance, by counting the animals present in a certain volume of the mud, or on a certain area of the bottom.

P. T. Cleve.

V. It seems to be of a certain importance to determine the amount of carbon (organic), nitrogen, sulphur, and phosphorus in the bottommud of the fishing-banks.

P. T. Cleve. 


\section{APPENDIX IV.}

\section{Marking of Fisues in the Waters of the Region of the Baltic} aNd the North Sea.

The marking of fishes in order to facilitate a systematic control and investigation as to their migrations and growth, and also to the periodicity and frequency of their spawning seasons, is, in most cases, to be regarded as the most certain and direct means of arriving at reliable and satisfactory conclusions. The method of marking salmon, already known and practised in Great Britain a number of years ago, has of late, for some ten years, been taken up and carried on in Norway, as may also have been the case in some of the other countries here represented. In Denmark the marking of plaice has been practised of late years. As to Sweden, it has been proposed and agreed upon more than once that such a proceeding ought to be more generally and methodically made use of, as, for instance, at the general conferences on questions regarding the fisheries of Sweden, held at Gothenburg and Stockholm in 1891 and 1897, when, at both those occasions, there were also present several distinguished specialists as representatives of the other Scandinavian countries; but this plan, although unanimously assented to and approved of, has nevertheless not as yet been carried into execution, owing perhaps to a certain extent to the circumstance of there not being any common plan and method of marking adopted for the whole Baltic region, a condition which was especially made an essential point of by the Stockholm Conference.

Being of opinion that the question of marking fishes, more especially of the different species of sea-salmon and flat-fish, and also, if possible, other kinds of fishes of all the coasts and waters of the different countries represented at this meeting, no doubt belongs to the competence of this Conference, and still more, when considering that there are some most distinguished gentlemen here present, being of unquestionable renown as specialists on this subject, I beg to propose that this question be admitted on the programme of the meeting in order to be duly discussed and decided upon according to circumstances.

Filip Trybom.

Sтоскноцм, June 14th, 1899. 